\title{
ITÁLICA ABOLIDA: UNA LECCIÓN DE VANITAS EN LA POESÍA ESPAÑOLA CONTEMPORÁNEA
}

José María FERRI COLL Universidad de Alicante

El afán por pervivir se contradice con la fragilidad de las obras del hombre y aun con la de su propia especie. De ahí que el sentimiento de la vanitas resulte medular en la reflexión filosófica y poética acerca de la existencia humana y su sentido. En las páginas que siguen he abordado con brevedad uno de los principales símbolos del topos clásico. Se trata de la poetización de las ruinas, una de las más bellas lecturas de la vanidad que la poesía contemporánea ofrece al lector. Unamuno glosó en Del sentimiento trágico de la vida las palabras de Spinoza que aludían al esfuerzo de la especie humana por perdurar:

Quiere decirse que tu esencia [...], la mía, la del hombre Spinoza, la del hombre Butler, la del hombre Kant y la de cada hombre que sea hombre, no es sino el conato, el esfuerzo que pone en seguir siendo hombre, en no morir (1993: 12).

La perseverancia en la conservación de la vida representa también la lucha constante por hallar respuestas con que llenar la sensación de vacío que azota a la sociedad contemporánea como si de una epidemia se tratara. Luis Antonio de Villena resumió su parecer ante el asunto en el poemario cuyo título simboliza la misma idea a que aludía antes: Huir del invierno (1981), libro sobre el que trataré después. Por su parte César Antonio Molina, remedando al poeta francés Patrice de la Tour du Pin, expresó en su poemario La estancia saqueada (1983) su particular visión del hombre moderno en que se convoca de nuevo el símbolo del frío ("vacío'): 
Estamos condenados a morir de frío

bajo los falsos aleros de las casas, como un país

que en la cuarentena de su niñez nonata ya no tiene leyendas

para espantar, ruinas para la lapidación, ni raíles

donde practicar las ordalías [...] (1991: 179).

La poesía contemporánea se ha servido del tópico antiguo, moldeándolo a su antojo, por la capacidad de éste para asociarse a las preocupaciones de cada edad. Las tres últimas décadas del siglo XX, como otros períodos finiseculares, han sido momento oportuno para la poetización del desengaño y la fugacidad del tiempo. A la crisis protagonizada por la lenta agonía del Franquismo y el trastabillado advenimiento de la democracia -en lo que a los acontecimientos históricos se refiere-, hay que añadir el debout de la nueva poesía apadrinada por Castellet en Nueve novísimos poetas españoles, antología en que se presentó en sociedad a los jóvenes recién desembarcados en la corte de los poetas. Tenían estos «jeunes Turcs» - marbete que usó Gimferrer para referirse a sus amigos renovadores (2001: 151) - la intención de defender su concepción del poema como símbolo y de justificar -o denunciar en algunos casos- su distanciamiento de la tradición poética española inmediatamente anterior a ellos. En palabras del antólogo:

Los planteamientos de los jóvenes poetas (en 1970) ni tan siquiera son básicamente polémicos con respecto a los de las generaciones anteriores: se diría que se ha producido una ruptura sin discusión, tan distintos parecen los lenguajes empleados y los temas objeto de interés (2001: 15-16).

En la mayoría de las «Poéticas» que los antologados escribieron como pórtico a los poemas seleccionados por Castellet, se percibe el desdén que éstos sentían hacia la literatura que en aquel momento se publicaba en España. En un país en que «sale el sol por Antequera»-en fina ironía de Carnero (2001: 200)-, en que el lastre de la dictadura perdurará por años, y en donde se echa de menos un magisterio poético, por no decir intelectual, capaz de convertirse en ejemplo para los nuevos creadores, la sensación de vacío se conjura mediante la fe en mitos foráneos y la redención por la palabra. Aunque la opinión de los incluidos en la antología de Castellet no fuera representativa de todas las tendencias poéticas que iban cuajando en los últimos estertores del Franquismo y los primeros balbuceos de la democracia, es preciso reconocer que, al menos, ésta sí era un sintoma de que una nueva sensibilidad estaba despuntando en el panorama literario español. La reflexión sobre las ruinas en este contexto de cambio y desamparo intelectual vino como anillo al dedo a quienes se acercaban a éstas como el humanista, que les habia otorgado un carácter sagrado (vestigia) en cuanto que eran testimonio de la Antigüedad. Esta se nos muestra imbricada en la arquitectura contemporánea, hecho que trastocarán sin posibilidad de enmienda los expolios y las reformas 
urbanísticas que acabaron definitivamente con la ilusión de una civilización continua y eterna, al arrimo del parecer de Eliot de que el presente no es patrimonio exclusivo de los contemporáneos, sino también de quienes contribuyeron a forjarlo en una suerte de continuidad de la vida y de las obras humanas, parecer que también resume el verso de Panero «el murmullo indecible de un tiempo que no muere» (Panero, 2001:437). Así se columbra en el ejemplo de las ruinas de Roma, engrandecidas si cabe por el mimo del Pontífice León X, pero arrasadas por el celo urbanístico de Sixto V, quien se afanó en la modernización de la ciudad rompiendo para siempre el equilibrio entre lo antiguo y lo moderno. Por eso mismo la Roma que conoció el palermitano Vitalis ya había mudado su fisonomía cuando en 1617 fue visitada por Quevedo, de ahí que el poeta español sólo halle desolación y ningún resto del esplendor antiguo. Por tanto las ruinas contempladas o imaginadas representan una ruptura en la sucesión de la civilización, pero, como ha demostrado Simmel (1988), una reconciliación con la Naturaleza, en tanto que los edificios que el hombre ha levantado a despecho de ésta, una vez arruinados, vuelven a fundirse en ella, como dicen los versos de Carnero que copio a continuación: «Sobre las piedras se abre / una fontana de musgo» (Carnero, 1983: 82). Se trata de alimentar la idea de que la vida se desarrolla en círculos y de que ninguna obra humana es perfecta, en su sentido etimológico de 'acabada'. Un razonamiento similar, atendiendo ahora a la creación poética, se halla en la «Nota del autor» con que Guillermo Carnero inaugura su Ensayo de una teoria de la visión:

En cuanto a los últimos poemas que aquí se incluyen, parte del libro inacabado Ensayo de una teoría de la visión, es pronto para pronunciarse sobre ellos, pero creo que no contradicen mi idea de cómo se desarrolla a lo largo del tiempo una obra coherente: no de modo lineal, sino en espiral, es decir retomando siempre los mismos problemas según una trayectoria circular que se salva de ser viciosa porque en cada ciclo hay una mayor complejidad que sintetiza el anterior recorrido y relee esa síntesis de modo más abarcador (Carnero, 1983: 72).

La complejidad del significado de las ruinas y las implicaciones metafísicas de sus diversas concreciones estéticas sedujeron a los poetas del 27 , entre quienes hay que nombrar a Luis Cernuda, quien en un manojo de sus mejores poemas - «A las estatuas de los dioses» (Invocaciones), «Las ruinas» (Como quien espera el alba), «Desolación de la quimera» del libro de igual título, «Otras ruinas» (Vivir sin estar viviendo), etc.- - se valió del lugar común otorgándole el rango de paraíso donde es posible no sólo la vida eterna, sino también la felicidad. Ha dicho con razón Prieto de Paula que los poetas del 27 idealizaron el sur y sus ciudades, que se convierten en símbolo del territorio inalcanzable donde habita lo que deseamos (Prieto de Paula, 1991: 240-241). Creo que comúlga con esta idea el poemario de 
L. A. de Villena Huir del invierno (1981), en cuya «Noticia preliminar» afirma sủ autor:

«Huir del invierno» es buscar las culturas del Sur y ese Sur mismo. Es decir, la truncada tradición del paganismo grecolatino [...] y también el helenismo [...]. «Huir del invierno» es, pues una quête. La búsqueda de todo lo que la luz y el meridiano representan. Y para mí, el intento de asumir vital y culturalmente lo que me gustaría ser y el mundo en el que quisiera habitar (Villena, 1996: 143).

A la significación de espacio para el deseo hay que añadir al topos su valor de dibujo de la muerte. Y al parafrasear el conocido poemario de Carnero quiero hacerme eco de las observaciones de Carlos Bousoño sobre la profunda reflexión que subyace en la obra acerca de la inanidad de las empresas humanas, abocadas a perecer (en Carnero, 1983: 42), aunque en una lectura superficial del libro pueda cegarnos el fogonazo de su belleza. En algunos poemas - «Amanecer en Burgos», «Capricho en Aranjuez», «El serenísimo príncipe Ludovico Manin contempla el apogeo de la primavera», etc.--, se aprecia la sensibilidad del poeta hacia los despojos del pasado así como la lección de vanidad que se desprende del ejemplo. En este sentido la aseveración del autor no puede ser más clara (Carnero, 1983: 112):

\section{Pero nadie}

dude hoy que el antiguo esplendor y la felicidad consisten en ungirse con los ricos despojos de sueños y cadáveres.

En los tres poemas citados se difumina el hiato entre vida y muerte gracias al constante reverdecer de la materia caduca, idea que Carnero expresa más tarde refiriéndose a un personaje egipcio en «Eupalinos», poema publicado en El azar objetivo (Carnero, 1983: 192):

En la tumba de Hatshepsuth se encontró entre el ajuar funerario una veintena de granos de trigo con aptitud germinativa.

Este maridaje ya se muestra en «Amanecer en Burgos» («Florece la altísima tumba»; «en la sombra germina / la floración de la carne muerta»; «albos sepulcros»; «armonioso vuelo de la piedra»); en «Capricho en Aranjuez» («Fuera hermoso morir»; «juego de piedra y agua»); y en «El serenísimo príncipe Ludovico...» («Viejos mármoles ultrajados por el monótono ronroneo del agua») (Carnero, 1983: 82, 104 y 112 respectivamente). El agua como símbolo de la vida, pero también de la inmutabilidad se contrapone con la piedra, imagen de las obras humanas condenadas a perecer. Repárese en el último verso citado: la aliteración 
de nasales (mármoles y monótono, ambos esdrújulos) contrasta con la violencia de oclusivas velares (viejos y ultrajados) y vibrantes (ultrajados y ronroneo), esto es se enfrenta lo que permanece a lo que fluye. Referido al río de Roma establece la misma paradoja Vitalis («Disce hinc quid possit Fortuna: immota labascunt, / et quae perpetuo sunt agitata manent») (en Ferri Coll, 1995: 26). El éxito de esta fórmula y su continuidad durante el Siglo de Oro son indudables. En francés, Du Bellay, y en español Quevedo se sirven del lugar común ( «iOh, Roma!, en tu grandeza, en tu hermosura, / huyó lo que era firme, y solamente / lo fugitivo permanece y dura») (Blecua, 1984:190). Y ya en el siglo XX, Ezra Pound en «Rome», publicado en 1911 en French Poems y Cernuda en «Las ruinas» retoman el motivo ( «En tanto el agua libre entre los juncos / pasa con la enigmática elocuencia / de su hermosura que venció a la muerte») (Cernuda, 1992: 193). La preocupación por la fugacidad de la vida en la generación poética del 70 ha sido descrita por Carlos Bousoño de manera precisa (en Carnero, 1983: 43-44). Ahora bien, en la experimentación de la temporalidad se invierte el proceso de creación, que ya no se funda en la contemplación de la realidad, de donde nace la emoción, y de ésta el poema, sino que el itinerario será, como dice Carnero, «no de la emoción al poema / sino al contrario» (Carnero, 1983: 204). Así se ha de entender la presencia de Cartago («Aeneidos liber IV, 1971»), Roma («Una ética del renunciamiento»), Troya («Giovanni Antonio Bazzi, "Il Sodoma"»), Babilonia («Extrarradial»), Segesta y Tauromenium, antiguas ciudades sicilianas («Viento del sur»), etc., en la poesía de Luis Antonio de Villena. El centro de interés en estos poemas no es la contemplación de las ruinas sino el exemplum que de ellas se colige.

Sepulcro en Tarquinia (1975) contiene un poema homónimo en el que me detendré un momento (Colinas, 1999: 104-118). Compuesto en endecasilabos blancos principalmente, su título rememora el hallazgo de una tumba etrusca en Tarquinia, hecho que quedaría relegado exclusivamente al terreno de lo arqueológico de no ser por la asociación del motivo con el tema amoroso, ayuntamiento canonizado por la poesía europea del Renacimiento. La anécdota del saqueo, que trata también César Antonio Molina en el poema «Y...Jornada triunfal para los saqueadores» (Molina, 1991: 105), trae a la mente del autor la reflexión sobre el amor no correspondido, o, como es el caso de Colinas, cercenado por la muerte. La chispa de la Antigüedad suelta la imaginación del poeta («salieron los caballos a la noche»), quien deshace los límites cronológicos entre presente y pasado en una suerte de pantemporalidad en que se confunden no sólo épocas sino también la propia sucesión lógica de los acontecimientos, dada la inclinación surrealista del autor. Si atribuimos a la influencia del Surrealismo la ilogicidad en el relato de la historia, al Romanticismo le debe Colinas el ambiente nocturno («la noche sumergió pechos y rosas / noche de madurez envuelta en nieve») y sepulcral («y con la bruma de los cementerios, y con los hierros de los cementerios, y con las 
nubes rojas allá arriba / [encima de cipreses y aves muertas, / del tomillo y los búcaros fragantes] / de los cementerios / navegando en tus ojos»). El poema, por lo dicho hasta aquí, solapa dos anécdotas, la personal y la histórica. La intersección entre ambas se halla en el sentimiendo de caída y destrucción que supone para la primera la muerte de la mujer amada, y para la segunda el expolio de la tumba. Repárese en que Colinas se separa de la tradición del género de ruinas en cuanto que atribuye la responsabilidad de la destrucción a su verdadero agente: el hombre, y no al tiempo o a Fortuna, como ocurre generalmente en los casos de Cartago, asolada por la guerra, y de Roma, expoliada por la codicia y la ignorancia:
debieron de robarles la custodia, los hachones de oro y aquel cáliz de ónice y pedrerias muy hermoso, debieron de picar todos los techos, artesonados, púlpitos altares [...]

La historia del expolio supone una desmitificación del topos clásico que Colinas acrecienta con la imagen de los rebaños paciendo entre las ruinas («el rebaño de cabras rumia siempre / abajo entre las ruinas de los templos»). Contrasta esta visión de las ruinas con la que procede de la imaginación del poeta que rebasa el estado contemporáneo de éstas idealizándolas hasta el punto de evocar instantáneas del momento en que florecieron: «Aún pasa por mi mente aquella villa / de Catulo que imaginamos juntos». En el proceso de idealización se produce la introducción en el poema de detalles tendentes al esteticismo y a la creación de una atmósfera de noble y serena belleza:

las muchachas más jóvenes bebían

las notas de Chopin y se olvidaban

del champagne espumoso de las copas,

[...]

pavos reales de luz de madrugada,

ruido de campanillas en el claustro, azucenas tronchadas en la senda, rojo cojín para aquel joven rubio que nunca echó las cartas que escribía, ataúd blanco para una dama triste.

Nótese en los versos copiados arriba la fruición con que Colinas mezcla la decadencia y el esplendor en su afán por pergeñar el retrato de la nada: vacío que se advierte en la construcción de un universo poético poblado de imágenes de decrepitud que tienen su razón de ser en la constatación por parte del poeta de la inutilidad de todo empeño humano por perdurar. Y como ejemplo la brevedad de la rosa y la fugaz espuma del champagne. Da la sensación de que no se puede 
aprehender la perfección, de que no se llega a conseguir el objeto de deseo: la tumba del soldado ha sido despojada de los bienes que atesoraba, la belleza natural es víctima de las inclemencias del tiempo, como se observa en el motivo del jardín en ruinas que nos trae a la memoria el Huerto deshecho de Lope, y la mujer muere antes de poseerla («morir sin poseerte qué delicia»), de ahí que el poeta sea consciente de que el paraíso de la belleza imperecedera queda vedado al género humano: «debes saberlo [...]: jamás llegará nadie a este lugar».

En 1979 Aníbal Núñez editó «Casa Lys», incluido en 1983 en Alzado de la ruina (Núñez, 1995: 253-256). Consagrado al conocido edificio salmantino que le da título, el poema repara en el estado de las cristaleras de su fachada modernista. Obsérvese que las ruinas en este caso ya no proceden del universo legendario de las series líricas dedicadas a urbes antiguas. El poeta se detiene ahora ante una ruina contemporánea. Los versos, agrupados en cinco series, no desembocan en ninguna conclusión, al contrario de lo que ocurre frecuentemente en el género, donde se cierra el poema con algún tipo de consideración moral. Las tres primeras series son descriptivas, y sólo en las dos últimas Aníbal Núñez introduce elementos narrativos que configuran una mínima historia inacabada y hermética por lo que a su contenido hace. En la parte descriptiva del poema, predomina la enumeratio, que es una constante en la poesía de ruinas. El autor se sirve de retahílas de vocablos que denotan el esplendor del edificio y su decaimiento actual a un tiempo. Y esa conjugación de lujo y muerte despierta en el lector el sentimiento de vacío de que he hablado al referirme a Dibujo de la muerte. Tanto la ausencia de una conclusión moral que ligue el exemplum de las ruinas a otros motivos afines o al sentimiento amoroso, como la prudencia con que el autor desnuda su emoción ante el edificio contemplado - lo que se hace patente en la falta de interjecciones y exclamaciones presentes en otros poemas de ruinas-, exageran la distancia entre el poeta y las ruinas. Más que el pasado solemne de la edificación, sorprende al poeta el postramiento en que yace el destartalado palacio («oriflama que congrega/ a los que exalta el desmoronamiento / acaso más que tu esplendor»), a pesar del cual todavía es posible observar en sus ventanas el reflejo de la luz, de ahí que el repertorio de imágenes redunde en la consideración de las vidrieras como espejos en que se mira la ciudad actual. Se inaugura éste en el primer verso ( «Colgante llamarada oblicua hacia poniente») donde se presenta la imagen central del poema que se reverbera en versos sucesivos («huerto de luz esmerilada», «copa de llamas», «ojos incendiados», «oriflama», «pedazo luminoso», «torre de azufre», 《ángel de ceniza», «globos de acetileno»). Paradójicamente las vidrieras en ruinas reflejan las luces de la ciudad en una suerte de continuidad entre vida y muerte que atestiguan tanto las numerosas imágenes de la destrucción («joya que claudica», «tibio cadáver», «sede de la tristeza», «fantasma volante», «febril palacio»), como las que encierran un oxímoron («lacre en los corazones en que se extingue 
y crece», «dulce es el ocaso», «altos muros leprosos», «talud de piedra enferma»). El contraste que se origina al asociar términos que aluden a ideas contrarias es la síntesis perfecta del significado del motivo de las ruinas: gloria y caída, fortaleza y decaimiento, orgullo y vanidad. El poeta, en fin, modula el tópico manteniendo algunos resortes retóricos y la polivalencia significacional que entraña el símbolo, pero huye de la modalidad lacrimosa del género en que el destino del objeto contemplado se asocia al del contemplador, quien no puede evitar el nacimiento del presagio de su propia muerte.

El poemario de Villena Como a lugar extraño recoge poemas compuestos entre 1985 y 1989, entre los que leemos «Placer de ruinas» (Villena, 1996: 342-344). El título se corresponde con el del libro de R. Macaulay Pleasure of ruins, que se publicó en Londres en 1953, y que ignoro si Villena había leído. Se trata de una silva libre de cincuenta y cinco versos de arte mayor y menor de distinta medida, aunque predominan el endecasílabo y el heptasílabo. Esta forma de verso libre en que se introducen reminiscencias clásicas no es extraña en la poesía del 70 , según ha demostrado Isabel Paraíso al ocuparse de la métrica de Nueve novisimos (Paraíso, 2001: 279-289). Se abre el poema con una enumeratio en que se nombran cuatro ciudades antiguas míticas (Troya, Roma, Itálica y Cartago). La presencia de la ciudad hispana nos hace sospechar por lo raro de acudir a mitos nacionales. Inmediatamente después, el poeta se dirige a su interlocutor poético -recurso este famoso en la poesía del género en que se alude al peregrino, caminante, o amigo a quien, en tono de confesión, se transmite la emoción sentida ante el espectáculo que regalan las ruinas-, que en este caso es el estudioso de la literatura española S. B. Vranich, quien, aparte de otros trabajos, publicó una antología de la poesía de ruinas en el Siglo de Oro (Vranich, 1981). La nota metaliteraria supone el distanciamiento de la realidad, porque el vocativo alude al autor del libro que interesa al poeta, y éste es elegido en tanto que antólogo, y no porque exista una vinculación afectiva entre ambos, por lo que se diluye la emoción personal y el valor subjetivo de la confesión. Comienza a abordar el tema realmente en el verso séptimo recreando una fórmula sintáctica repetida hasta la saciedad en nuestra lírica áurea: «Este que hoy te enseño». El verso nos lleva inmediatamente al arranque de la hermosa Canción a las ruinas de Itálica de Rodrigo Caro (Blecua, 1984: 148-151): «Estos, Fabio, ¡ay dolor!, que ves ahora». En el poema de Villena el verso queda despojado de la fuerza mostrativa que tiene en la Canción de Caro porque no abre el poema. El poeta contemporáneo persigue un fin muy distinto del utrerense. En la Canción, una serie de deícticos perfectamente emplazados nos sitúan ad oculos el escenario que contempla Caro, de ahí que sea capital un inicio contundente del poema. Y esto es lo que propicia el hipérbaton en que se interponen entre el demostrativo y su núcleo seis palabras, todas ellas seleccionadas y ordenadas apropiadamente. Villena intercala dos menos: una de ellas es el 
vocativo, la otra la exclamación. Y en este punto se puede advertir cuán diferente fin persiguen ambos poetas. Intencionadamente el autor de «Placer de ruinas» obvia la referencia sentimental, el desgarro que sale del poeta de Utrera, que, ya como arqueólogo, ya como anticuario y coleccionista, se había sentido atraído por la ciudad antigua. La referencia temporal es idéntica (ahora / hoy) y cumple una función primordial en el género, a saber: la contraposición entre el presente y el pasado, que aparece en seguida:

\begin{tabular}{|l|l|}
\hline \multicolumn{1}{|c|}{ Villena } & \multicolumn{1}{|c|}{ Caro } \\
\hline $\begin{array}{l}\text { Este que hoy te enseño, } \\
\text { chico torvo, en esguince, y de mirar callado, } \\
\text { fue un tiempo delicia, } \\
\text { dulce vegetal de amantes. }\end{array}$ & $\begin{array}{l}\text { Estos, Fabio, iay dolor!, que ves ahora } \\
\text { campos de soledad, mustio collado, } \\
\text { fueron un tiempo Itálica famosa. }\end{array}$ \\
\hline
\end{tabular}

La transgresión del modelo es clara. El objeto del poema de Villena ya no es la ciudad antigua sino la decadencia de un joven apuesto que ha perdido su mancebez. E1 tono elegíaco se suaviza con la introducción de notas prosaicas: «gastó dinero en tonto y por la noche», «paseó motos mil y otros mil lechos», «me encandilan aún y me dan guerra». Caro envilece la magnificencia de las ruinas introduciendo elementos antimiticos como los zarzales y lagunas que ahora sustituyen el laurel y los jazmines del jardín antiguo, o los lagartos que ocupan la morada «para el César fabricada». Lo propio hace Villena: «Ahora es joven ruina, / ruina nueva en la que corren los lagartos». Se ofrece el retrato de la decrepitud fisica de quienes gozaron del favor de la juventud al tiempo que se introduce la anécdota confesional que rompe con la reserva sentimental y la contención al emocionarse del arranque del poema:

Este Leif ya grueso y algo calvo

-portento antañoeste Julio rufianesco, y rosa antigua,

fueron de nuevo míos, por morbo y sin conciencia.

Lo mismo ocurre en la nota de vanitas que cierra el poema. Es notable la predilección de Villena por la ironía -procedimiento estudiado en detalle por Prieto de Paula (1996: 112-117)-, que, a pesar del endecasílabo gongorino último, logra desvaír el tono elegíaco que predomina en la silva de Caro:

Pero aunque me deleite

la ciudad devastada y la faz con surquitos

(el talle es más desgracia) 
es veraz sin fisura el escarmiento:

Somos ruinas futuras (y seguras)

que es el tiempo -Góngora dixit-

verdugo de murallas y bellezas.

El poema que acabo de comentar contiene, como si de un collage se tratara, elementos diferentes dotados de autonomía: el recuerdo del título de la obra de Macaulay, el revival de la Canción de Caro, el exemplum de las ciudades devastadas, la nota de vanitas, y el recuerdo implícito del carpe diem. Y es al analizar cada parte del collage cuando se entiende mejor la actitud irreverente ante el mito clásico de las ruinas que nace ya en el guiño inicial del título del poema.

La poesía del gallego César Antonio Molina indaga en la arquitectura antigua con el objetivo de reconstruir con el proceder del arqueólogo, que sólo tiene conocimiento fragmentario de la realidad que estudia, la estampa del tiempo ido con el ejemplo de las ciudades preferidas por el poeta. La vocación de Molina por la poesía arqueológica no es nueva ni tampoco el tono elegíaco que sobresale en muchos de sus versos. No en vano uno de sus primeros libros se tituló Proyecto preliminar para una arqueologia de campo (1978) -emulando la obra homónima de Alain Robbe-Grillet-. Más tarde, en Derivas (1987), el autor divide la materia en cinco apartados, que como teselas extraídas de un mosaico, evocan diferentes símbolos de la ciudad: «Carcasona», «Gobierno de un jardín», «Vieja cima», «Derivas» $\mathrm{y}$ «Ciudades suspendidas». En el primero despunta la ciudad arruinada y reconstruida, mientras que el segundo se adentra en la dicotomía acción / contemplación, y por fin los tres últimos aluden a espacios conocidos por el poeta en diferentes viajes. Como constatación de la ruina contemporánea y al mismo tiempo como desmitificación de la ruina clásica, el poeta presenta en el poema «Factorías», recogido en el último libro mencionado, un ejemplo de arqueología contemporánea. El arranque del poema compila símbolos inequívocos de desolación, pero evita la mostración deíctica habitual en el género de ruinas. El lector se sitúa ante el escenario por sus propios ojos y no a través de la mirada del poeta. La deíxis ad oculos, que tan buenos resultados había dado en grandes poemas como la Canción de Caro o célebres sonetos de Quevedo, es sustituida en este caso por la descripción del viento - nótese la aliteración de silbantes-:

El viento se desliza libre por el desierto blanco sin penetrar el secreto del agua transitoria.

Otra vez ha batido las branquias de las lenguas muertas como negro pez que navega por el turbio acuario impregnándolo todo de dulce letargo.

El léxico - «desierto», «lenguas muertas», «pez negro», «turbio acuario»-, nos introduce en un ambiente de soledad y muerte, que viene recalcado por el oxí- 
moron «dulce letargo», que me trae a la memoria el grabado de Durero Melancolía $I$, donde las figuras son víctimas de la melancolía, padecer que las conmina a la inactividad y el decaimiento. Sólo el agua «transitoria» fluye, aunque ignoremos cuál es el secreto de su inmortalidad, por eso no se puede «penetrar». En este teatro se presentan las ruinas de una vieja factoría abandonada:

En las bases abandonadas

todavia hay recuerdos en muy buen estado,

las antiguas construcciones de las factorías,

los barriles de aceite,

los botes para la captura,

las gloriosas empresas que corren hacia la luz

y cuya deserción la noche castiga.

El asta de los honores a la deriva

bajo un fuerte olor a excremento de animales que,

como parásitos,

se trasladan sobre los témpanos.

Y grandes cantidades de huesos de ballenas

flotan en tu boca como púas de gramófono.

Los años apenas han coloreado esos restos blanqueados

por la sal, cubiertos por la nieve (1991: 270-271).

Fiel esta vez a la retórica del lugar común, Molina describe mediante la enumeratio los distintos elementos que descuellan en el paisaje: «antiguas construcciones», «barriles», «botes»... El léxico nos acerca en seguida a la actividad pesquera. Es notable la exaltación que exhibe el poeta de la tristeza de las cosas. La acumulación de objetos que propicia la enumeración y el aparecer éstos desprovistos de su función habitual y abandonados de la mano que otrora los gobernaba, recuerda otra vez el grabado de Durero al que he aludido antes, en que las herramientas de trabajo yacen postradas en el suelo. Y entre los restos más nobles de la factoría relacionados con las labores de la pesca, aparecen otros elementos desmitificadores: «un fuerte olor a excremento», «grandes cantidades de huesos de ballenas»... La presencia del esqueleto animal, ejemplo último de vanitas, recuerda el destino inexorable de la especie humana. Sorprende el símil intuitivo «huesos de ballenas» como «púas de gramófono», tal vez motivado por la imagen de los discos de vinilo en movimiento circular como la vida misma. El poema se clausura con una estructura bimembre violentada por el encabalgamiento, que rompe la armonía. El color blanco de la sal y de la nieve, ambas poseedoras de cualidades conservantes, se opone al tinte negro que triunfa al principio del poema. En definitiva se trata de presentar la circularidad de la vida y la muerte, gobernada por la dictadura de la Naturaleza, que condena a las especies a reproducirse y perecer constantemente. La vida no ha conseguido vencer a la muerte, pero sí al olvido: por eso todavía se puede ver en la vieja factoría el cúmulo de 
restos inmortalizados por la sal y la nieve. En este punto, Molina se acerca a la idiosincrasia del lugar común, que ofrece al lector las señales que rescatan del olvido el rigor de la muerte.

Reflejo contemporáneo de una sociedad que se regodea de su propio perecer, la ruina es síntoma de abatimiento moral, pero también de la indolencia con que el parnaso español del 70 estampó la fugacidad de la especie humana. Por eso el símbolo de Venecia, que Thomas Mann había habilitado para la sensibilidad del hombre del final del milenio en La muerte en Venecia, se repite hasta la saciedad en la poesía de la década del 70 en adelante: «Oda a Venecia ante el mar de los teatros» (1966), de Gimferrer; «Muerte en Venecia» (1967) y «Museo naval de Venecia» (1990), de Carnero; «Venecia» (1987), de César Antonio Molina, etcétera. En un tiempo en que era menester que todo cambiara para que la vida siguiera igual, la poesía ofrece la estampa de la existencia como si ésta fuera travesía sorprendida por el naufragio, según el decir de Shelley:

Nada más permanece. Y en torno a la ruina del colosal naufragio, sin limites, se extiende la arena lisa y sola que en el principio era. 234):

El mismo parecer gravita en dos versos de Luis Alberto de Cuenca (1999:

No hay huellas de pisadas humanas en la arena.

La ciudad es el resto de un naufragio terrible.

En el otoño del siglo XX, uno de los motivos más recurrentes en la poesía española es el sentimiento de la vanitas, del que se desprende una nota de nihilismo. El escenario vacío que describe el poema de este género representa el interior del hombre que sigue buscando tierra firme en donde pisar. Y diríase que sólo con el ungüento de la belleza sana la herida de la desolación y se restablece el poder de la antigua grandeza abolida. 


\section{BIBLIOGRAFÍA}

Blecua, José Manuel (ed.), Poesia de la Edad de Oro II. Barroco, Madrid, Castalia, 1984.

Carnero, Guillermo, Ensayo de una teoría de la visión (Poesía 1966-1977), Madrid, Hiperión, 1983.

Castellet, J. M. (ed.), Nueve novisimos poetas españoles, Barcelona, Península, 2001 (1970).

CERnuda, Luis, La realidad y el deseo. 1924-1962. Madrid, Fondo de Cultura Económica, 1992.

Colinas, Antonio, El rio de sombra. Treinta años de poesía, 1967-1997, Madrid, Visor, 1999.

CuenCA, Luis Alberto de, Los mundos y los dias. Poesía 1972-1998, Madrid, Visor, 1999.

FERri Coll, José María, Las ciudades cantadas. El tema de las ruinas en la poesía española del Siglo de Oro, Alicante, Universidad, 1995.

MaCaulay, Rose, Pleasure of ruins. Londres, Weindenfeld and Nicolson, 1953. Molina, César Antonio, Las ruinas del mundo, Barcelona, Anthropos, 1991.

NúÑ̃E, Aníbal, Obra poética I, Madrid, Hiperión, 1995.

Panero, Leopoldo Maria, Poesía completa. 1970-2000, ed. de Túa Blesa, Madrid, Visor, 2001.

PARAíso, Isabel, «Las elecciones métricas de los nueve novísimos», en E. A.

Salas Romo (ed.), De sombras y de sueños. Homenaje a J. M. Castellet, Barcelona, Península, 2001, pp. 279-289.

PRieto De PaUla, Ángel L., La lira de Arión. De poesía y poetas españoles del siglo XX, Alicante, Universidad, 1991.

- Musa del 68. Claves de una generación poética, Madrid, Hiperión, 1996.

Simmel, George, «Las ruinas», en Sobre la aventura. Ensayos filosóficos, Barcelona, Península, 1988, pp. 117-125.

Unamuno, M. de, Del sentimiento trágico de la vida, Barcelona, Planeta, 1993 (1913).

Villena, Luis Antonio de, La belleza impura. Poesia 1970-1989, Madrid, Visor, 1996.

VRANiCH, Stanko B. (ed.), Los cantores de las ruinas en el Siglo de Oro, El Ferrol, Esquío, 1981. 